\title{
Os discursos políticos em relação à Covid-19 e a emergência por uma alfabetização científico-tecnológica: encontros e desencontros no cenário brasileiro
}

\section{Political discourses in relation to Covid-19 and the emergence of an scientific and technological literacy: encounters and disagreements in the brazilian scenario}

\author{
${ }^{1}$ Nara Alinne Nobre-Silva nara.silva@ifgoiano.edu.br \\ ${ }^{2}$ Antonia Adriana Mota Arrais
}

\section{RESUMO}

O presente artigo tem por objetivo apresentar e discutir as diferentes vozes que retratam as medidas adotadas para o controle e tratamento da COVID-19, no decorrer de março a meados de maio de 2020. Para a discussão, buscam-se interlocuções com a Alfabetização Científico-Tecnológica (ACT), que carrega em si a promoção de uma formação crítica e participativa. O estudo se caracteriza como qualitativo, do tipo descritivo. Como fonte de dados, foram selecionadas e transcritas entrevistas, coletivas e pronunciamentos proferidos por representantes dos governos municipal, estadual e federal, além de ocupantes de diferentes cargos do Ministério da Saúde. Adiante, submeteu-se à Análise Textual Discursiva. Os resultados indicam que as dissonâncias entre os discursos governamentais inauguraram uma avalanche de (des)informação, que acabou por conduzir parte da população a seguir posturas inadequadas. Em algumas instâncias, houve uma consciência coletiva, sobressaindo as recomendações da ciência em detrimento de "achismos”. Além disso, resplandeceram indícios de que a economia é o fator preponderante e que na corrida pela cura da doença, o governo federal tem minimizado os estudos clínicos que revelam riscos do uso da (hidroxi)cloroquina. Por fim, evidencia-se que a ACT, enquanto processo, torna-se uma estratégia plausível para o enfrentamento de olhares e atitudes que se encontram com o negacionismo e a anticiência, movidos mais por ideologias e crenças, do que pela análise crítica e complexa da realidade existente. Palavras-chave: Anticiência. Alfabetização Científico-Tecnológica. COVID-19.

\begin{abstract}
This article aims to present and discuss the different voices portraying the measures adopted for the control and treatment of COVID-19, between March through mid-May, 2020. For the discussion, the aim is to seek interlocutions with Scientific and Technological Literacy (STL), which carries in itself the promotion of a critical and participative formation. The study is characterised as qualitative, of the descriptive type. As a source of data, interviews were selected and transcribed, press conferences and statements made by representatives of municipal, state and federal governments and occupants of different positions in the Ministry of Health. Subsequently, it was submitted to Discursive Textual Analysis. The results indicate that the dissonances between the government speeches inaugurated an avalanche of (dis) information, which eventually led part of the population do follow inadequate postures. In some instances, there was a collective consciousness, highlighting the recommendations of science to the detriment of "guesswork". Also, there were signs that the economy is the predominant factor and that in the race to cure the disease, the federal government has minimized clinical studies that reveal risks of (hydroxy) chloroquine use. Finally, Scientific and Technological Literacy (STL) as a process becomes a plausible strategy for confronting the looks and attitudes that meet denialism and antiscience, driven more by ideologies and beliefs than by critical and complex analysis of existing reality.
\end{abstract}

Keywords: Antiscience. Scientific and Technological Literacy. COVID-19.

1 Doutoranda em Educação em Ciências pela Universidade de Brasília, professora de Química na Educação Básica Técnica e Tecnológica no Instituto Federal Goiano Campus Iporá.

2 Doutoranda em Educação em Ciências pela Universidade de Brasília, professora de Ciências Naturais na Secretaria de Estado de Educação do Distrito Federal. 


\section{PRIMEIRAS PALAVRAS: CONTEXTUALIZANDO O ESTUDO}

Este trabalho é dedicado a apresentar os diferentes discursos políticos brasileiros proferidos entre início de março a meados de maio de 2020, em relação às medidas de controle e tratamento do novo coronavírus. Por conseguinte, evidenciar como a Alfabetização Científico-Tecnológica (ACT) se consolida como importante processo frente à formação crítica. Por isso, organizamos o presente estudo a partir da seguinte questão: "De que forma os discursos políticos brasileiros, em relação às medidas de controle e tratamento da COVID-19, evidenciam a emergência de uma sociedade Alfabetizada Científica e Tecnologicamente?”. Este questionamento nos conduz a indagações secundárias: "O que é a COVID-19? Quais discursos políticos brasileiros têm sido veiculados na mídia em relação ao enfrentamento (ou não) da pandemia? De que forma a ACT pode contribuir para a adoção de posturas mais coerentes frente à pandemia?”.

Acreditamos que uma sociedade precisa ser alfabetizada científica e tecnologicamente, isto porque "a alfabetização científica, ao fim, revela-se como a capacidade construída para a análise e avaliação de situações que permitam ou culminem com a tomada de decisões e posicionamentos" (SASSERON, 2015, p. 56). Dessa forma, é imprescindível que os processos educativos subsidiem a formação de cidadãos que atuem crítica, política e coletivamente diante das ambiguidades vivenciadas em uma sociedade capitalista, na qual o lucro, o consumo e o capital valem mais do que a vida do povo. Nesse sentido, a ACT pode contribuir para que os cidadãos em situações catastróficas e de calamidade, como a da pandemia de COVID-19, tenham condições de apreciar e tomar decisões diante dos conteúdos disseminados por meio de vários discursos.

No que se refere ao discurso político, Rasquel (2018), no estudo de três propagandas do governo anterior relativas à Reforma da Previdência, indica como ele atua como ferramenta de manipulação, em consequência da desinformação do cidadão. Esclarece que esse tipo de discurso carrega aspectos persuasivos e de convencimento, que contribui para a formação de opiniões, atitudes e conhecimentos do grupo controlado. Por conseguinte, direta ou indiretamente, influencia que o grupo adote posicionamentos baseados na posição ideológica de quem transmite tais (des)informações. Atualmente, no âmbito da pandemia, acreditamos que para além da desinformação, o excesso de informações falsas e a pouca ACT conduzem os cidadãos a defenderem medidas que já se mostraram ineficientes em outros países ou até mesmo a desacreditarem da letalidade da situação.

Diante da atual conjuntura, o presente escrito tem como objetivo apresentar e discutir as diferentes vozes que retratam as medidas adotadas para o controle e tratamento da COVID-19 no contexto brasileiro. Assim, buscamos interlocuções com a ACT, que carrega em si a promoção de uma formação crítica. Destacamos trechos de discursos proferidos por representantes dos governos municipal, estadual e federal, além de ocupantes de diferentes cargos do Ministério da Saúde. Utilizamos como fonte de dados as entrevistas, as coletivas e os pronunciamentos transmitidos por plataformas de compartilhamentos de vídeos e sites jornalísticos e oficiais, tendo como intervalo os meses de março a meados de maio do ano de 2020. Adiante, os mesmos foram submetidos a técnica de Análise Textual Discursiva (ATD) (MORAES; GALIAZZI, 2016).

\section{O NOVO CORONAVÍRUS: SITUANDO A PROBLEMÁTICA...}

Em dezembro de 2019, foram registrados na cidade de Wuhan, província de Hubei, na República Popular da China, os primeiros casos de uma síndrome respiratória aguda grave, resultado do novo coronavírus (SARS-CoV-2), que é responsável pela doença COVID-19 (LANA et al., 2020). Conforme destacam Fehr e Perlman (2015), coronavírus (CoVs) são vírus de ácido ribonucleico (RNA) com sentido positivo, causadores de uma variedade de doenças em mamíferos e aves, dos quais alguns possuem potenciais patógenos em humanos. As pessoas infectadas com esse vírus podem apresentar, em diferentes graus, febre, tosse, dores no corpo, mal-estar, cansaço, coriza, dificuldade respiratória e dor de cabeça, e alguns outros sintomas não tão comuns, como diarreia e vômito. No entanto, ainda existem casos assintomáticos, nos quais os infectados não sentem nenhum incômodo e mesmo assim podem transmitir a doença para outros indivíduos (OMS, 2020). 
No caso da COVID-19, chamou a atenção sua velocidade de propagação e infecção. No final de janeiro, países como Estados Unidos, Canadá e Austrália já registravam casos, o que levou a Organização Mundial da Saúde (OMS) a emitir no dia 30 desse mesmo mês, uma alerta sobre a epidemia. Com a disseminação geográfica, crescente e rápida, no dia 11 de março de 2020, o diretor-geral da OMS considerou o estado da contaminação a nível de pandemia, com pequenas cadeias de transmissão em alguns países e com extensas cadeias em outros, como Itália, Estados Unidos da América, Espanha e Reino Unido (ANDERSON et al., 2020; OMS, 2020).

No Brasil, no dia 26 de fevereiro, o Ministério da Saúde confirmou o primeiro caso em São Paulo, cujo paciente relatou histórico de viagem à Itália, um dos países em que estava ocorrendo um grande número de infectados e mortes (BRASIL, 2020). Assim, em meados do mês de março, governadores de estados como São Paulo, Goiás e do Distrito Federal, com respaldo das orientações da OMS e do Ministério da Saúde, efetuaram medidas para evitar aglomerações de pessoas. A citar: suspensão do funcionamento de instituições escolares e universidades, cancelamento de grandes eventos, atividades coletivas de cinemas, shows e teatros. Adiante, foram instituídas outras medidas protetivas para evitar a rápida proliferação do novo coronavírus, o isolamento e o distanciamento social, bem como restrições de transportes aéreos e rodoviários, priorizando que apenas as pessoas que estão na linha de frente ao combate da COVID-19 pudessem ter acesso a tais serviços.

O isolamento social é uma medida que tem como objetivo separar as pessoas infectadas e as suspeitas das não doentes por no máximo 14 dias. Já o distanciamento social visa a redução do contato entre indivíduos de uma comunidade para desacelerar a velocidade de propagação do vírus. Na atualidade, também é rotineiro encontrarmos os termos quarentena e lockdown. O primeiro refere-se à restrição de atividades ou separação de pessoas que foram expostas a situações de risco por contaminação. O lockdown (termo em inglês que se refere a bloqueio total) é um artifício para quando as medidas de isolamento, distanciamento e quarentena forem insuficientes. Corresponde a restrição total da interação entre pessoas de uma mesma região, por um curto período de tempo (TELESSAUDERS, 2020).

Esse conjunto de intervenções teve como um de seus principais objetivos evitar o colapso do Sistema Único de Saúde (SUS), ainda numa fase inicial da pandemia, uma vez que os hospitais públicos não possuem leitos de Unidade de Terapia Intensiva (UTI) suficientes para receber uma grande quantidade de infectados em estágios mais graves, nos quais precisam de respiradores mecânicos. Com isso, algumas equipes do governo, principalmente em âmbito estadual e municipal, traçaram planos para ampliar esses leitos, obterem testes rápidos para o controle e diagnóstico da COVID-19 em casos suspeitos, adquirirem respiradores mecânicos e equipamentos de proteção individual e coletiva (EPI) e (EPC), respectivamente, a fim de garantir o atendimento urgente das pessoas com quadros mais avançados. Além do mais, essas estratégias adotadas podem ser importantes para achatar a curva epidêmica, como também para minimizar a morbidade e mortalidade associadas à COVID-19, até a formulação de vacinas em larga escala ou terapias medicamentosas efetivas (ANDERSON et al., 2020; BEDFORD et al., 2020).

No entanto, tais ações geraram controvérsias entre os governos municipais, estaduais e federal. Inauguraram-se, diante das medidas impostas, uma avalanche de discursos e recomendações dissonantes entre os representantes de tais segmentos políticos-administrativos, deixando parte significativa dos cidadãos brasileiros desorientados, inseguros e divididos em relação à adoção de posturas necessárias e condizentes para o controle da pandemia.

Por um lado, algumas narrativas revelam sintonia com as evidências científicas, sendo alinhadas às orientações propostas pela OMS, embasadas em estudos recentes da área de virologia, epidemiologia, infectologia, microbiologia e também alinhadas com as experiências de outros países que conseguiram reduzir o número de casos e mortes por meio de medidas preventivas como o distanciamento e isolamento social, como é o caso da China (AINSLIE et al., 2020). Por outro, declarações no plano executivo federal, pouco fundamentadas cientificamente, minimizando os efeitos da doença a de uma "gripezinha"; desqualificaram o distanciamento e isolamento social e a restrição de abertura de atividades comerciais não essenciais, sob a justificativa de que os prejuízos econômicos conduziriam a resultados mais catastróficos do que a própria pandemia. Ou seja, essas condutas 
evidenciam um alinhamento ao modelo econômico de sociedade capitalista, no qual privilegia a produção e acumulação de riquezas, o lucro, o consumo desenfreado em detrimento ao bem estar social (LAYRARGUES, 2014). Mourão (2020), apesar de elucidar que não se posiciona como pró-isolamento ou anti-isolamento, tece críticas ferrenhas a essa orientação, apontando alguns aspectos negativos que emergem com essa prática, como o aumento de danos a saúde mental, depressão, ansiedade, crise do pânico, dentre outros, e ainda propõe o seguinte questionamento: "Será que vale a pena adiar a morte por vírus e deixar que as pessoas morram de fome?”. O levantamento dessas situações evidenciam a urgência não pelo fim do isolamento, mas pelo estabelecimento de condições e políticas públicas que priorizem a vida de modo integral, uma vez que [...] "escolher o lado da vida é combater não apenas a recessão ou o coronavírus, mas, de fato, garantir que todos tenham acesso a serviços básicos para uma vida plena” (COSTA; SILVA, 2020, p. 19).

Diante de tantas controvérsias expõe-se a relevância de processos educativos que vislumbrem a formação de cidadãos críticos que sejam capazes de analisar e avaliar os argumentos veiculados, tomar decisões e adotar posicionamentos que sejam alinhados com as premissas científicas e ainda para se organizarem coletivamente com o intuito de exigir que os agentes governamentais ajam em consonância com as necessidades sociais e em prol da saúde pública, como é no caso da COVID-19. Assim, para que estes sujeitos não encontrem ressonância com declarações baseadas em "achismos", "inverdades" e "fake news", uma das possibilidades é apostar em processos educativos que priorizem a ACT, conforme já ressaltado por autores como Auler e Delizoicov (2001), Auler (2003) e Santos e Auler (2019).

\section{ALFABETIZAÇÃO CIENTÍFICO-TECNOLÓGICA: ALGUMAS CONSIDERAÇÕES}

Considerando que a ACT é carregada por uma pluralidade semântica (SASSERON; CARVALHO, 2016), esclarecemos que, no presente estudo, nos aproximamos dos significados atribuídos por Auler (2003), uma vez que reconhece a educação científica como uma possibilidade de propiciar uma leitura crítica, aprofundada e complexa do mundo contemporâneo. Conjuntamente, Lorenzetti e Delizoicov (2001, p. 48) apontam que essa premissa é importante, tendo em vista que possui o potencial de tornar [...] "o indivíduo alfabetizado cientificamente nos assuntos que envolvem a Ciência e a Tecnologia, ultrapassando a mera reprodução de conceitos científicos, destituídos de significados, de sentidos e de aplicabilidade”. Consequentemente, permite ao sujeito o entendimento das ambiguidades dos processos de produção da Ciência e Tecnologia (CT), tornando-o capaz de avaliar, argumentar e tomar decisões sobre problemáticas que ensejam conhecimentos concernentes às ciências.

Há de se considerar que, nas últimas décadas, as descobertas científicas e o avanço tecnológico têm, ainda que de forma velada, provocado transformações nas formas como se estabelecem e se concretizam as relações sociais, políticas, culturais e econômicas, daí a emergência por uma ACT. Nesse ínterim, é preciso descortinar as reais implicações da CT, compreender que elas não são neutras, mas orientadas por interesses políticos, culturais, religiosos, sociais e econômicos. Assim, torna-se importante vislumbrar a correlação existente entre as ciências, os "seus conhecimentos e adventos tecnológicos e seus efeitos para a sociedade e o meio ambiente" (SASSERON; CARVALHO, 2016, p. 66) e como estão imbuídos de valores que remetem ao contexto que foram concebidas e produzidas (AULER, 2003; SANTOS; AULER, 2019).

Também cabe salientar que para além disso, a CT não estão necessariamente a favor das classes desfavorecidas e das minorias e por isso é essencial que haja um desvelamento da realidade e uma leitura crítica do mundo para que com isso ocorra a superação da percepção ingênua dos fatos e, assim, a instauração de uma educação que seja de fato problematizadora e libertadora (AULER; DELIZOICOV, 2001; FREIRE, 2013). A questão que se coloca é: como construir uma imagem mais realista da CT e subvencionar a participação social em problemáticas que atingem diretamente nossas vidas?

A partir de Auler e Delizoicov (2001), indicamos que, de antemão, é necessária a clarificação de alguns "mitos" subjacentes à produção do conhecimento científico e tecnológico, dos quais particularmente destacam- 
-se três: i) superioridade do modelo de decisões tecnocráticas; ii) perspectiva salvacionista da CT e iii) determinismo tecnológico. O primeiro mito guarda em si o cientificismo e a crença de que a Ciência é um conhecimento superior aos demais. As decisões relacionadas à CT não são abertas e debatidas com a população e/ou seus representantes, pois não há espaço para a democracia. Acredita-se que os especialistas técnicos, a partir de uma atuação neutra e livre de interesses, encontrarão soluções para os problemas sociais. Já o segundo incide sobre a concepção de que CT resolverá todos os problemas existentes e os que vierem a surgir, afinal elas visam o bem estar social. Em suma, congregam duas dimensões: o desenvolvimento da CT necessariamente conduz ao progresso e sempre são criadas para solucionar problemas. O terceiro mito alia a ideia de inovação tecnológica como fator fundamental para a mudança e o progresso social, e considera a tecnologia como autônoma e independente em seu desenvolvimento (AULER; DELIZOICOV, 2001).

Intencionando superar essas visões ingênuas, no sentido de caminhar rumo à possibilidade de decisões mais democráticas e participativas no que tange à CT, em uma leitura e compreensão crítica do mundo contemporâneo, Auler (2003) argumenta a favor do ensino dialógico e problematizador, cujo alicerce encontra-se ancorado na concepção educacional de Paulo Freire. Outrossim, Auler e Delizoicov (2001) enfatizam que o aprendizado precisa conduzir ao educando uma visão crítica da situação real vivida em um viés que busca não a conformação e imobilização perante às contradições sociais, mas o engajamento e a luta pela constante transformação do mundo. Para tanto, propõem a ACT em uma perspectiva ampliada, que se fundamenta na compreensão crítica das interações entre Ciência-Tecnologia-Sociedade (CTS). Em consonância, práticas educativas CTS têm se fortalecido, sinalizando, entre outras, a superação do determinismo científico-tecnológico, a compreensão de que valores interferem na definição de agendas de pesquisa e a necessidade da participação social nos rumos dessas investigações científicas e no desenvolvimento científico e tecnológico (SANTOS; AULER, 2019).

\section{PERCURSO METODOLÓGICO}

A presente investigação situa-se no conjunto das pesquisas qualitativas, visto que possui como característica a centralidade no processo e não no resultado, sem exprimir preocupação com representações numéricas (LUDKE; ANDRÉ, 2013). Quanto aos procedimentos, a pesquisa se enquadra como descritiva, uma vez que tem como principal objetivo compreender, caracterizar e descrever os fenômenos da realidade que se apresentam de modo complexo (GIL, 2002). Logo, o fenômeno que será analisado consiste nos discursos políticos em relação à COVID-19, em especial ao que se refere às medidas de contenção da pandemia e o tratamento da doença, utilizando como intervalo os meses de março a meados de maio de 2020.

Para tal, como estratégia de coleta de dados, utilizamos os seguintes procedimentos: i) seleção de canais de transmissão e veiculação (textual e audiovisual) de entrevistas, coletivas e pronunciamentos dos governos municipal, estadual e federal e do Ministério da Saúde, bem como plataformas de compartilhamento de vídeos (Youtube), sites CNN Brasil e da Presidência da República; ii) análise preliminar e delimitação dos materiais audiovisuais e textuais à luz do nosso problema de investigação e iii) transcrição dos vídeos. Dessa forma, compõe nosso corpus as transcrições de dezoito vídeos e os pronunciamentos do atual presidente, emitidos em cadeia nacional de rádio e TV, nos dias 06, 12 e 24 de março e 08 e 16 de abril de 2020 (a descrição dos materiais utilizados está disposta no Quadro 1, disponível em: (https://docs.google.com/document/d/1XQJPuY9_Iw5uHOSugpLWpybx7ohzmwWUl9LT355JrsM/edit?usp=sharing).

Para a análise dos dados, nosso corpus foi submetido à ATD, tendo em vista que a intenção da pesquisa foi buscar novas compreensões e a reconstrução de conhecimentos existentes (MORAES; GALIAZZI, 2016) a partir dos discursos explicitados nas citadas fontes. As etapas da ATD compreenderam: i) desconstrução e unitarização - leitura aprofundada das transcrições para construir as unidades de análise que receberam seus respectivos códigos identificadores. Os códigos foram formados pelas abreviações das fontes utilizadas (CNN, por exemplo) articuladas a dois numerais, no qual o primeiro tem o propósito de diferenciar reportagens e pronunciamentos dentro um mesmo veículo (CNN1), e o segundo, de posicionar a unidade de significado no material textual 
ou audiovisual analisado, formando assim a codificação completa (CNN1.6); ii) categorização - organização, ordenamento e agrupamento das unidades de análise semelhantes para elaboração de categorias pertinentes à intenção da pesquisa e iii) captação do novo emergente - elaboração de metatextos analíticos constituídos de descrição e interpretação que foram articulados com o referencial teórico explicitado.

\section{RESULTADOS E DISCUSSÃO}

O processo da ATD tem como desenlace a construção de um novo texto, em que emerge a "compreensão do pesquisador sobre os significados e sentidos construídos a partir" dos textos iniciais (MORAES; GALIAZZI, 2016, p. 53). Dessa forma, do nosso corpus de análise surgiram quarenta e sete unidades de significados, em que foram agrupadas em três categorias finais emergentes: 1) "Fique em casa": o isolamento social como estratégia não farmacológica; 2) Economia: vida x lucro; 3) (Hidroxi)cloroquina: achismos x ciência. Adiante, descrevemos e interpretamos as diferentes vozes que ora se encontram, ora se desencontram durante as medidas adotadas para o controle e tratamento do novo coronavírus.

\section{1 "Fique em casa": o isolamento social como estratégia não-farmacológica}

Durante a pandemia, a principal orientação emitida pelas instituições científicas, para conter a velocidade de propagação do novo coronavírus, diz respeito ao isolamento social horizontal. Após essa recomendação e também baseados nas experiências de outros países, vários líderes governamentais do Brasil adotaram posicionamentos e ações múltiplas em relação a essa estratégia. Alguns representantes, mesmo não obtendo apoio de figuras importantes do governo federal, optaram por unir esforços para a construção de ações interventivas para a contenção da doença, como: i) elaboração de decretos que proibiam as aglomerações e o funcionamento de estabelecimentos não essenciais; ii) campanhas para incentivar o isolamento social - “fique em casa, se puder”; iii) construção de hospitais de campanha com leitos de UTI; iv) busca por equipamentos e respiradores mecânicos e v) flexibilização de feriados, dentre outras medidas. A articulação nas propostas evidencia que os discursos e ações do prefeito e governador de São Paulo em relação à contenção da pandemia eram ressonantes, como pode ser observado nas seguintes unidades de análise:

GOVPA1.1- (...)“Nós dependemos basicamente da cooperação do entendimento da sociedade, de cada cidadão, de cada cidadã, que cada um deles tem um dever primeiro de proteger a sua saúde, e nos auxiliar a cuidar da saúde toda a sociedade. Então mais do que nunca ficar em casa essa é a mensagem essencial”. (Governador do Estado de São Paulo em 06/04/2020).

JTVC1.2- (...)“A ideia agora é antecipar os feriados municipais, como já mencionei no dia de ontem, hoje inclusive, a partir das 15h, a câmara municipal começa a debater o projeto”. (Prefeito de São Paulo em 18/05/2020)

Essa atitude demonstra que esses líderes governamentais, assim como alguns representantes de outros estados, com uma consciência coletiva, seguiram as recomendações da ciência e não agiram baseados em "achismos” ou em pura opinião pessoal. Tais figuras políticas agiram de modo contrário ao governo federal e seus apoiadores, que insistem em se ancorar em um fundamentalismo religioso - evidencia um desprezo pela ciência; político - abomina qualquer forma de pensamento crítico; e econômico - que os aspectos econômicos imperam sobre todas as coisas (FRIGOTTO, 2020).

É diante dessa situação que a ACT, enquanto processo, pode ser crucial para a formação de cidadãos que pautem suas ações e organizem seu pensamento de maneira lógica e crítica, possibilitando assim novas forma de ver, ser e transformar o mundo, por meio de uma prática consciente e cerceada de saberes e conhecimentos científicos (SASSERON; CARVALHO, 2016). Com esse viés formativo, dificilmente um indivíduo compactuaria com medidas impostas por entidades políticas que são envoltas por interesses que não são comprometidos com 
a saúde e bem estar social, como é visto diante de alguns fatos expostos perante a pandemia, a citar a defesa por um isolamento que seja vertical:

CNN1.6- (...)“O próprio Mandetta já conversei com ele, tá convencido que isso agora que eu disse para vocês, a quarentena vertical ou confinamento vertical”. (Presidente do Brasil em 26/03/2020)

BANDJ1.4- (...)“Desde o começo devia ser vertical. É cuidar das pessoas do grupo de risco e botar o povo para trabalhar”. (Presidente do Brasil em 13/05/2020)

Tais pronunciamentos demonstram uma orientação que evidencia uma preocupação maior com os impactos econômicos que emergirão devido à ação de "ficar em casa”. Por meio do discurso CNN1.6, é possível notar que o chefe de Estado parece ter tentado conversar com o ex-ministro da saúde acerca da possibilidade de adotar o isolamento vertical como um caminho alternativo, mas ao não obter sucesso nesse caso, e também diante da insistência para que este defendesse o uso de medicamentações duvidosas para a COVID-19, Luiz Henrique Mandetta acabou sendo exonerado do cargo.

Com o isolamento vertical, a proposta é que apenas as pessoas do grupo de risco evitem a exposição ao vírus. A intenção é possibilitar que a população aumente sua imunidade em relação a COVID-19, para com isso reduzir o número de casos, a chamada "imunidade de rebanho". Essa medida é um tanto quanto preocupante e ineficaz, uma vez que os indivíduos do grupo de risco poderão ter contato no ambiente domiciliar com pessoas não isoladas e assim se contaminarem (SCHUCHMANN, 2020).

\section{2 Economia: vida $x$ lucro}

A discordância com o isolamento social horizontal demonstrou indícios de que a economia é o fator preponderante do plano de governo que está em curso, visto que mesmo diante de uma crise sanitária, em que milhares de brasileiros estão perdendo as suas vidas, discursos como estes são veiculados constantemente:

CNN1.4- (...)“Lamentavelmente, a nossa vida, né? Tem um dia que ela se esvai. Então o que acontece a grande onda é desemprego, essa segunda onda chegou aí e quando de fala de desemprego, se fala de economia”. (Presidente do Brasil em 26/03/2020)

CNN4.1 - (...)“E daí? Lamento. Quer que eu faça o quê? Eu sou Messias, mas não faço milagre”. "Mas é a vida. Amanhã vou eu”. (Presidente do Brasil em 29/04/2020)

Essas declarações parecem evidenciar a favor de quem e de que lado o governo está. O risco de contrair o coronavírus não é tão democrático quanto aparenta ser, posto que a classe trabalhadora que não possui a opção de exercer suas atividades laborais em casa se expõe mais aos riscos por não poder se isolar ou ficar em quarentena sem o auxílio do Estado (HARVEY, 2020). Dessa forma, não há dúvida que "os mais afetados serão os pobres das grandes metrópoles, apinhados em favelas”. Parece que a campanha aqui do Brasil é alicerçada com o que aconteceu inicialmente em Milão - Milão não para - no entanto, por lá houve um arrependimento e por aqui, algumas pessoas ainda estão imbuídos por uma visão de que "não importa quantos irão morrer, o que importa é salvar a economia. O que não se diz é: os lucros do patronato mais poderoso e rico e do capital financeiro" (FRIGOTTO, 2020, p. 3), a ver pelos discursos explicitados nas unidades CNN1.4 e CNN4.1. 
Pelo visto, tudo vale para atender aos interesses dos grandes empresários e bilionários, desmoralizar as ações adotadas pela maioria dos estados e municípios e ainda minimizar a letalidade da doença:

PRON3.1 - (...)“O sustento das famílias deve ser preservado. Devemos, sim, voltar à normalidade. Algumas poucas autoridades estaduais e municipais devem abandonar o conceito de terra arrasada, a proibição de transportes, o fechamento de comércio e o confinamento em massa”. (Presidente do Brasil em 24/03/2020)

PRON3.3 - (...)“No meu caso particular, pelo meu histórico de atleta, caso fosse contaminado pelo vírus não precisaria me preocupar, nada sentiria ou seria, quando muito, acometido de uma gripezinha ou resfriadinho, como bem disse aquele conhecido médico daquela conhecida televisão". (Presidente do Brasil em 24/03/2020)

É em um contexto como este que deve-se haver a luta pela democratização dos conhecimentos, partindo da compreensão que em uma sociedade alfabetizada científica e tecnologicamente, os cidadãos pautarão suas ações e posicionamentos com uma consciência crítica em relação às contradições vividas e as questões de saúde emergentes, reconhecendo-se assim como seres que podem atuar e transformar a realidade que não é ingênua/ mágica (AULER; DELIZOICOV, 2001). Mas que é envolta por práticas neoliberais, que com “ares de pós-modernidade, insiste em convencer-nos de que nada podemos contra a realidade social que, de histórica e cultural, passa a ser ou virar "quase natural” (FREIRE, 2017, p. 21).

É por meio de uma educação problematizadora, emancipatória e libertadora (FREIRE, 2013) que os seres humanos terão a capacidade de se organizarem, coletivamente e dialogicamente, para o enfrentamento de políticas e ações governamentais que são ancoradas em princípios que privilegiam as demandas e interesses da classe dominante, em detrimento da elaboração de propostas que busquem a justiça e a inclusão em uma sociedade marcada por tantas desigualdades sociais, como é o caso da brasileira. A citar a situação atual, no qual nota-se um descaso do governo federal com essas populações, uma vez que somente após intensiva pressão da oposição, logo tardiamente, este buscou alternativas para auxiliar as pessoas diante da pandemia, mas ainda com um discurso mais vertido para a "volta ao trabalho", do que incentivando o isolamento social para a contenção da COVID-19:

PRON5.2 - "A partir de amanhã, começaremos a pagar os R\$ 600,00 de auxílio emergencial para apoiar trabalhadores informais, desempregados e microempreendedores durante três meses. Concedemos, também, a isenção do pagamento da conta de energia elétrica aos beneficiários da tarifa social, por 3 meses, atendendo a mais de 9 milhões de famílias que tenham suas contas de até $\mathrm{R} \$ 150,00$ ”. (Presidente do Brasil em 08/04/2020)

\section{3 (Hidroxi) cloroquina: achismos $x$ ciência}

A partir de meados de março de 2020, ganhou repercussão um artigo francês que apresentou dados a respeito do uso da hidroxicloroquina e azitromicina no tratamento da COVID-19 (GAUTREAT et al., 2020). Ainda que o estudo tivesse ocorrido com um pequeno número de pacientes e os dados não fossem conclusivos, a notícia se disseminou rapidamente. Nesse mesmo mês, aqui no Brasil, o Ministério da Saúde e a Agência Nacional de Vigilância Sanitária emitiram notas informando respectivamente o uso da cloroquina como adjuvante no tratamento de formas graves da doença (Nota Informativa ${ }^{\circ}$ 5/2020) e a liberação de pesquisas com o uso de hidroxicloroquina em casos leves e moderados. Mas o que é a cloroquina e a hidroxicloroquina? A cloroquina é um composto aromático, derivada da 4-aminoquinolona. Durante a Segunda Guerra Mundial, foi amplamente utilizada na profilaxia e tratamento da malária. Desde 1955, sua utilização tem se expandido no combate ao lúpus e artrite reumatóide. A hidroxicloroquina é um composto com características similares, no entanto, com menos efeitos adversos (GOLDHARDT et al., 2002; MENEZES; SANCHES; CHEQUER, 2020). 
No contexto desses estudos iniciais, representantes governamentais de países como os Estados Unidos e o Brasil, em uma espécie de corrida pela cura da COVID-19, emitiram opiniões favoráveis ao uso do fármaco. Já representantes transeuntes do Ministério da Saúde, impeliam em seus discursos uma relativa dicotomia sobre o remédio: ora ressaltando a existência dos efeitos colaterais e o caráter ainda experimental, ora relegando aos médicos a responsabilidade de prescrever, por iniciativa individual, o medicamento (TVBRA1.5). Há de se mencionar que, durante os meses de março e abril, sites jornalísticos como Correio Brasiliense (CORREIO BRASILIENSE; 2020), Uol (LIDNER; SABINO, 2020) e CNN (VENAGLIA, 2020) veicularam notícias que lançaram luz aos desalinhamentos entre o Presidente do Brasil e o ministro da saúde, no que tange à (hidroxi)cloroquina. Por outro lado, pesquisadores, profissionais da área da saúde e governadores de estado estimularam discussões acerca dos riscos do uso do fármaco, salientando a necessidade de estudos experimentais mais abrangentes sob um esperado rigor científico.

Colocamos em pauta que os discursos políticos guardam uma possibilidade de poder, que pode ser exercido de forma positiva ou negativa. O uso e o abuso desse poder envolvem, entre outros, o controle e a manipulação, fazendo com que o ouvinte construa modelos mentais tendenciosos e representações sociais e ideológicas (RASQUEL, 2018). Nesse ínterim, apresentamos os excertos abaixo, a fim de ilustrar as diferentes vozes que circunscrevem o período de março a maio de 2020:

TVBRA1.4- (...)acho que se o Brasil conseguir dar essa agilidade essa escalada que nós queremos, nós podemos muito bem organizar o nosso e salvar vidas de outros países, vizinhos ou distantes, que ou ainda não conseguiram se preparar minimamente ou que não tem o mínimo de materiais, e o parque industrial brasileiro pode sim dar essa resposta, ao mesmo tempo que estamos trabalhando com universidades, com grupos para bolarmos respiradores mais portáteis que eu brinco: vamos fazer um fusquinha e vamos colocar isso na mão dos médicos uma coisa simples, facilitada”. (Ministro da Saúde em 22/03/2020)

TVBRA1.5- (...) "história da cloroquina (...) já monitorávamos isso desde a primeira produção que tivemos (...) ainda no mês de fevereiro. Havia indícios e continuamos como indícios, são poucos pacientes tratados, não sabemos se o medicamento foi decisivo ou não para o caso, precisa ser feito em maior escala”. (Ministro da Saúde em 22/03/2020)

DNTV1.4- “Ah pode ser em proporção maior proporção menor, quem cabe decidir não é o presidente da república, muito menos a prescrever cloroquina na porta do palácio. Isso é decisão médica nós é que sabemos como deve ser estabelecido o protocolo, quantos casos estão usando cloroquina e foram a óbito. Então isso não é uma verdade absoluta” (Governador do Estado de Goiás em 25/03/2020)

TVBRA2.3- "No momento o que a gente faz é disponibilizar para aqueles pacientes de gravidade média, de gravidade avançada, e a prescrição médica no Brasil a caneta e o CRM do médico está na mão dele. Se ele quiser comunicar ao paciente dele: olha não tenho nenhuma evidência, acho que poderia usar esse medicamento com tal risco e tal risco, tal risco, podemos ter isso, isso, isso e se responsabilizar individualmente, não tem óbice nenhum. Ninguém vai reter receita de ninguém”. (Ministro da Saúde em 07/04/2020)

BANDJ1.2- "No meu entendimento, ouvindo os médicos é que ela deve ser usada desde o início por parte daqueles que integram o grupo de riscos, pessoas que têm comorbidades, pessoas de idade, deve ser usada a hidroxicloroquina... Repito a vocês, se fosse a minha mãe, minha mãe está com 93 anos de idade eu vou atrás dela pego o médico, lógico que não vou forçar o médico, tem muito médico que concorda com esse tipo de medicamento, que seria medicamento, e ela usaria a hidroxicloroquina. Enquanto não tivermos algo comprovado no mundo, temos esse no Brasil. Aqui que pode dar certo e pode não dar certo”. (Presidente do Brasil em 13/05/2020)

Os trechos destacados clarificam que, no decorrer da pandemia, várias vozes marcam o episódio da (hidroxi)cloroquina, o que nos conduz a uma questão central que envolve qual trajetória percorrer. É importante demarcar que a escolha desse caminho não pode se consolidar por ideologias políticas ou por opiniões indivi- 
duais baseadas em "achismos”. Observamos no trecho DNTV1.4 que o governador do estado de Goiás, no mês de março, criticou a postura do Presidente do Brasil de advogar a favor do uso do medicamento, ressaltando a possibilidade de óbito, pois os estudos estavam numa fase exploratória. Contudo, a defesa não foi abandonada, pois elevou-se a produção de hidroxicloroquina pelo Laboratório Químico Farmacêutico do Exército e continuaram as declarações de que a mesma era a solução para a COVID-19 e, embora o protocolo de testes não estivesse finalizado, parabenizou o médico Dr. Roberto Kalil por usar o medicamento no tratamento de dezenas de pessoas. O excerto BANDJ1.2, já do mês de maio, mostra o presidente narrando um caso fictício, que em segundo plano, pode guardar uma tentativa de sensibilizar as pessoas para legitimar o uso da (hidroxi)cloroquina. Esses discursos são preocupantes, uma vez que os ouvintes podem, erroneamente, acreditar que a prescrição é segura. Não obstante, em março, após veiculações de possíveis efeitos positivos do fármaco, a população imersa em um misto de (des)informação, começou a comprá-lo equivocadamente, o que levou o Ministério da Saúde a emitir nas coletivas alertas de seus efeitos colaterais e a definir que a venda de medicamentos a base de (hidroxi)cloroquina ficassem sujeitos à receita de controle especial em duas vias ( $\left.R D C n^{0} 351,20.03 .2020\right)$.

Para além das opiniões individuais, defendemos um caminho articulado às orientações fundamentadas em pesquisas científicas. Longe de (re)afirmar uma concepção salvacionista de Ciência (AULER; DELIZOICOV, 2001), pois não desconsideramos suas limitações, implicações, seu caráter político, econômico e social. Acreditamos que, no que se trata essencialmente do cuidado com a vida em tempos de pandemia, a pesquisa científica, sob seu esperado rigor, pode indicar caminhos mais seguros para o enfrentamento do novo coronavírus.

Embora a confiança que se atribui à Ciência, suas pesquisas e seus resultados não são verdades absolutas, conforme bem ressaltou o governador do estado de Goiás (DNTV1.4). Contudo, vivemos um período que frases como "é preciso ouvir a ciência”, "temos que respeitar o método científico", têm se tornado verdadeiros slogans. Nos preocupa que essas concepções se tornem máximas e que a ideia de ciência neutra, objetiva, a que muitos anos o ensino de ciências tenta superar, sejam fortalecidas. Neste seguimento, a ACT, em suas diferentes dimensões, prática, cívica e cultural (SHEN, 1975 citado por LORENZETTI; SIEMSEN; OLIVEIRA, 2017) corrobora para concitar visões críticas sobre a Ciência, assim como para a participação no debate público e na tomada de decisões.

Ademais, Goldenberg (2007, p. 420) anuncia que “a medicina é a ciência das verdades transitórias muitas vezes transformadas em dogmas para fins didáticos” e, que grandes verdades e condutas adotadas no passado, historicamente se tornaram inverdades. Há de se colocar em questão um acontecimento que elucida claramente esse caráter efêmero: no dia 27 de maio, apregoou-se a notícia (G1.GLOBO, 2020) de que o governo francês revogou o decreto que autorizava a administração de hidroxicloroquina no tratamento de pacientes infectados pelo novo coronavírus, sob a justificativa de um estudo publicado pela The Lancet (MEHRA et al., 2020), que indicava o aumento do risco de morte e de desenvolvimento de arritmia cardíaca. Dias após, a comunidade científica começou a questionar a veracidade dos dados apresentados no artigo em questão e, por incoerência na base de dados fornecida por determinada empresa, o mencionado artigo foi retirado do ar. No entanto, outros estudos, como o publicado no dia 3 de junho pelo The New England Journal of Medicine (BOLWARE et al., 2020), vem indicando a pouca ou nenhuma eficácia da (hidroxi)cloroquina e, alerta ainda acerca das complicações que podem ser geradas por meio dos seus efeitos colaterais.

Esses acontecimentos são reflexos de pesquisas coletivas, quedas de braço entre fatores humanitários e mercadológicos, bem como de investimentos em CT. Lamentavelmente, aqui no país, nos últimos anos, se instalaram medidas de supressão da pesquisa. As universidades públicas/institutos, responsáveis por grande parte da produção científica e tecnológica, e que muito se fizeram presentes nos discursos dos representantes (transeunte) do Ministério da Saúde, têm assistido recorrentemente à corte de verbas, modificação de regras de distribuição de bolsas de pós-graduação que acarretam perdas (CAPES, Portaria $n^{\circ} 34$ - 2020) e redução de financiamento de pesquisas na área de Ciências Humanas (MCTIC, Portaria $n^{\circ} 1.122$ - 2020). No que tange a esta última, Ramos e Silva (2020), fundamentados em Nussbaum (2015), denunciam que as decisões tomadas pelo governo Bolsonaro não são medidas isoladas, mas estão em consonância com um movimento maior que, ao arrefecer as 
artes e humanidades, atacam a formação integral em suas diferentes dimensões, assim como coloca em jogo, a sobrevivência da democracia.

Considerando o exposto, surge uma nova questão: como o Brasil se posiciona frente aos resultados dos novos estudos internacionais? No dia 25 de maio, quando ainda circulava o estudo publicado pela The Lancet, a OMS emitiu nota de suspensão de testes com a (hidroxi)cloroquina no tratamento da COVID-19. Entretanto, circularam nos sites O Globo (2020), Estadão (BULLA, 2020) e Cidade Verde (2020), informações de que, no dia 31 de maio, o Brasil firmou parceria com o governo americano para receber 2 milhões de doses para o tratamento da doença. Após retirada do artigo publicada pela The Lancet, o noticiário Folha de São Paulo (PINTO, 2020) divulgou que a própria OMS anunciou que "retomará" os testes com os medicamentos. Esses fatos ilustram que a Ciência, produzida por homens e mulheres, possui caráter transitório, subjetivo e está sujeita à falhas. Por questões temporais, os desencadeamentos a seguir não serão tratados neste estudo, mas farão parte da história das medidas governamentais para o combate e tratamento do novo coronavírus. Há de se destacar que, nesse contexto, a mídia tem cumprido papel importante na difusão de informações sobre a pandemia, revelando uma responsabilidade social. Contudo, como bem assinala Livianu (2009), no mundo contemporâneo, a mídia tem poder tanto para formar quanto para deformar. Acreditamos que essa possibilidade de deformação se faz ainda mais latente no contexto das fake news. Inclusive, o cuidado com as fake news foi mencionado pelo ministro da saúde, na coletiva do dia 01 de abril, uma vez que estava circulando a existência de uma falsa campanha de doação para o enfrentamento da pandemia. Nessa conjuntura, reafirma-se a emergência de uma sociedade alfabetizada científica e tecnologicamente, que tenha condições de avaliar e se posicionar sobre o conhecimento veiculado, como também compreenda as relações e interdependências entre conhecimento científico e práticas sociais.

\section{CONSIDERAÇÕES FINAIS}

Os discursos apresentados, no período de início de março a meados de maio de 2020, refletem os desalinhamentos entre as esferas política-administrativas, que em segundo plano ora se aproximam, ora se distanciam. Neste movimento, observamos um segmento envolto por olhares e atitudes que se encontram com o negacionismo e a anticiência, movidos mais por ideologias e crenças, do que pela análise crítica, profunda e complexa da realidade existente. Já o segundo se mostra mais alinhado às orientações da comunidade científica, da OMS, e demonstram uma maior preocupação com o bem estar social.

Nesta conjuntura, os processos educativos ancorados na ACT fortalecem uma possibilidade plausível para o entendimento, o enfrentamento e a resistência, de forma ética e democrática do cenário de pandemia. Pois um cidadão alfabetizado científico-tecnologicamente se torna capaz de buscar fontes seguras para compreender conceitos e recomendações básicas que envolvem a CT, em relação a problemática em questão, por exemplo: i) o que é e como funciona o novo coronavírus; ii) a importância de adotar medidas de isolamento e de higiene específicas, como o uso de máscaras de tecido; iii) o processo de produção de vacinas e imunização e iv) o perigo dos efeitos colaterais emergidos pela ingestão de medicamentos que não são destinados para o tratamento da COVID-19. Em uma perspectiva mais ampliada, deseja-se também que o mesmo reconheça como funcionam as pesquisas científicas e a importância de investimento nestas, assim como também as limitações e implicações da CT. Então, com esses entendimentos, acreditamos que o cidadão talvez não encontre ressonâncias em suas atitudes e decisões com determinadas vozes políticas que foram ecoadas ao longo desse estudo.

Ler e analisar esses discursos políticos, assim como ver os posicionamentos e reações das pessoas diante destes, já que não tem como dissociarmos essas falas dos impactos que elas causaram nos rumos da pandemia no Brasil, nos inspiraram as mais variadas reflexões que podem servir de encaminhamentos para futuras pesquisas: "Por qual(is) motivo(s) alguns cidadãos preferem pautar suas decisões baseadas em discursos negacionistas e anticientíficos disseminados por políticos e não na CT?”; “Em quais aspectos a escola, mesmo reconhecendo que ela não é capaz de solucionar todos os problemas que emergem na sociedade, tem sido frágil ao não priorizar a formação de sujeitos que sejam alfabetizados científico-tecnologicamente?” e “O que nós professores, enquanto 
sujeitos formadores, em um contexto tomado pelas ideias do projeto 'Escola sem Partido', podemos fazer para garantir uma formação que seja de fato crítica, política e científico-tecnologicamente?’.

\section{REFERÊNCIAS}

AINSLIE, K. E. C. et al. Evidence of initial success for China exiting COVID-19 social distancing policy after achieving containment. Wellcome Open Research. p.1-10, 2020.

ANDERSON, R. M.; HEESTERBEEK, H.; KLINKENBERG, D.; HOLLINGSWORTH, T. D. How will countrybased mitigation measures influence the course of the COVID-19 epidemic? The Lancet, v. 395, 931-934, 2020.

AULER, D. Alfabetização Científico-Tecnológica: um novo “paradigma”? Ensaio-Pesquisa em Educação em Ciências. v. 5, p. 68-83, 2003.

AULER, D; DELIZOICOV, D. Alfabetização científico-tecnológica para quê? Ensaio Pesquisa em Educação em Ciências. v. 3, n. 2, p. 122-134, 2001.

BEDFORD, J.; ENRIA, D.; GIESECKE, J.; HEYMANN, D. L.; IHEKWEAZU, C.; KOBINGER, G. COVID-19: towards controlling of a pandemic. The Lancet. v. 395, p. 1015-1018, 2020.

BOLWARE, D. R. et al. A randomized trial of hydroxychloroquine as postexposure prophylaxis for Covid-19. The New England Journal of Medicine. Disponível em: https://www.nejm.org/doi/full/10.1056/NEJMoa2016638. Acesso em: 24 out. 2020.

BRASIL - Ministério da Saúde. Brasil confirma primeiro caso da doença. 2020. Disponível em: https://www. saude.gov.br/noticias/agencia-saude/46435-brasil-confirma-primeiro-caso-de-novo-coronavirus. Acesso em: 20 março 2020.

BULLA, B. Casa Branca anuncia envio de 2 milhões de doses de hidroxicloroquina para o Brasil. O Estadão, 2020. Disponível em: https://saude.estadao.com.br/noticias/geral,casa-branca-anuncia-envio-de-2-milhoes-dedoses-de-hidroxicloroquina-para-o-brasil,70003320511. Acesso em: 24 out. 2020.

CORREIO BRASILIENSE. Mandetta: estudo da ação da cloroquina contra coronavírus é muito frágil. Correio Brasiliense, 2020. Disponível em: https://www.correiobraziliense.com.br/app/noticia/brasil/2020/04/03/internabrasil,842260/mandetta-estudo-da-acao-da-cloroquina-contra-coronavirus-e-muito-fra.shtml. Acesso em: 24 out. 2020.

CIDADE VERDE. EUA enviam 2 milhões de doses de cloroquina ao Brasil. Cidade Verde, 2020. Disponível em: https://cidadeverde.com/coronavirus/108170/eua-enviam-2-milhoes-de-doses-de-cloroquina-ao-brasil. Acesso em: 24 out. 2020.

COSTA, J. B, SILVA, L. H. A. É preciso escolher entre vida e economia? Revista Pet Economia UFES, 1(1), 17-19, 2020.

FEHR, A. R.; PERLMAN, S. Coronaviruses: an overview of their replication and pathogenesis. Methods Molecular Biology, v.1282, p.1-23, 2015.

FREIRE, P. Pedagogia da autonomia. Saberes Necessários à Prática Educativa. 25ª Edição. Paz e Terra, 1996.

P. Pedagogia do oprimido. Rio de Janeiro: Paz e Terra, 2013.

FRIGOTTO, G. Empresários mais ricos do Brasil: a ignorância, o cinismo e a ganância que matam. Espaço e Economia - Revista brasileira de geografia econômica, 2020. 
GAUTREAT, P. et al. Hydroxychloroquine and azithromycin as a treatment of COVID-19: results of an openlabel non-randomized clinical trial. Jounal Pre-proof, 2020.

GIL, A. C. Como elaborar projetos de pesquisa. São Paulo: Atlas, 2002.

GOLDENBERG, S. Reflexões sobrea verdade. Acta Cirúrgica Brasileira, editorial, v.22, n.6, p.420-421, 2007.

GOLDHARDT, R. et al. Avaliação da toxicidade ocular por derivados da 4-aminoquinolona. Arq. Bras. Oftalmologia, n.65, p.645-649, 2002.

HARVEY, D. Política anticapitalista em tempos de COVID-19. In: DAVIS, M.; HARVEY, D.; BIHR, A.; ZIBECHI, R.; BADIOU, A.; ZIZEK, S. Coronavírus e a luta de classes. Terra sem Amos: Brasil, 2020.

LANA, R. M.; COELHO, F. C.; GOMES, M. F. da C.; CRUZ, O. G.; BASTOS, L. S.; MACIEL, D. A.; CODEÇO, C. T. Emergência do novo coronavírus (SARS-CoV-2) e o papel de uma vigilância nacional em saúde oportuna e efetiva. Cadernos de Saúde Pública, v. 36, p. 1-5, 2020.

LAYRARGUES, P. P. A dimensão freireana na educação ambiental. In: LOUREIRO, C. F. B.; TORRES, J. R. Educação Ambiental: dialogando com Paulo Freire. São Paulo: Cortez, 2014.

LINDNER, J.; SABINO, M. Estudo sobre cloroquina é ainda incipiente, diz Mandetta. Uol, 2020. Disponível em: https://noticias.uol.com.br/ultimas-noticias/agencia-estado/2020/03/28/estudo-sobre-cloroquina-e-aindaincipiente-diz-mandetta.htm. Acesso em: 24 out. 2020.

LIVIANU, R. Mídia e Cidadania. coord. Justiça, cidadania e democracia (on-line). Rio de Janeiro: Centro Edelstein de Pesquisa Social, 2009. pp. 202-212. SciELO Books. Disponível em: https://static.scielo.org/ scielobooks/ff2x7/pdf/livianu-9788579820137.pdf. Acesso em: 05 maio 2020.

LORENZETTI, L.; DELIZOICOV, D. Alfabetização científica no contexto das séries iniciais. Ensaio Pesquisa em educação em Ciências, v. 3, n. 1, p. 37-50, 2001.

LORENZETTI, L.; SIEMSEN, G. H.; OLIVEIRA, S. Alfabetização Tecnológica na Educação em Química: analisando a temática ácidos e bases. Actio, v.2, n.1, p.4-22, 2017.

LUDKE, M.; ANDRÉ, M. E. D. A. Pesquisa em educação: abordagens qualitativas. 2º ed. São Paulo: EPU, 2013.

MEHRA, M. R. et al. Hydroxychloroquine or chloroquine with or without a macrolide for treatment of COVID-19: a multinational registry analysis. The Lancet, p.1-10, 2020.

MENEZES, C. R.; SANCHES, C.; CHEQUER, F. M. D. Efetividade e toxicidade da cloroquina e da hidroxicloroquina associada (ou não) à azitromicina para tratamento da COVID-19. O que sabemos até o momento? Journal of Health and Biological Sciences, v.8, n.1, p.1-9, 2020.

MORAES, R.; GALIAZZI, M. C. Análise Textual Discursiva. 3ºd. Ijuí: Ed. Unijuí, 2016, 264p.

MOURÃO, C. A. J. COVID-19 e isolamento social: algumas reflexões. Revista Augustus, v. 25, n. 51, p. 381393, 2020.

NUSSBAUM, M. Sem fins lucrativos: por que a democracia precisa das humanidades. São Paulo: WMF Martins Fontes, 2015.

O GLOBO. Estados Unidos anunciam envio de 2 milhões de doses de cloroquina para o Brasil. O Globo, 2020. Disponível em: https://oglobo.globo.com/sociedade/estados-unidos-anunciam-envio-de-2-milhoes-dedoses-de-cloroquina-para-brasil-24455665. Acesso em: 24 out. 2020. 
ORGANIZAÇÃO MUNDIAL DE SAÚDE (OMS). Folha informativa - COVID-19 (doença causada pelo novo coronavírus). Disponível em: https://www.paho.org/bra/index.php?option=com_ content\&view=article\&id=6101:covid19\&Itemid=875. Acesso em: 24 maio 2020.

PINTO, A. E. S. OMS vai retomar estudos com hidroxicloroquina após avaliação de segurança. Folha de São Paulo on-line, 2020. Disponível em: https://www1.folha.uol.com.br/equilibrioesaude/2020/06/oms-vairetomar-estudos-com-hidroxicloroquina-apos-avaliacao-de-seguranca.shtml. Acesso em: 24 out. 2020.

RAMOS, R. L. M.; SILVA, C. N. N. Ensino Médio Integrado: por que o Brasil precisa dele? In: CRUZ SOBRINHO, S.; PLÁCIDO, R. L. Educação Profissional Integrada ao Ensino Médio (org), João Pessoa: IFPB, 2020, cap.1 p.25-47.

RASQUEL, S. G. A desinformação como estratégia de manipulação e abuso de poder no discurso político. Letras Escreve, v.8, n.2, p.7-32, 2018.

SANTOS, R. A.; AULER, D. Práticas educativas CTS: busca de uma participação social para além da avaliação de impactos da Ciência-Tecnologia na sociedade. Ciência e Educação, v. 25, n.2, p.485-503, 2019.

SASSERON, L. H. Alfabetização Científica, Ensino por Investigação e Argumentação: relações entre Ciências da Natureza e a Escola. Ensaio, v.17, nº especial, p.49-67, 2015.

SASSERON, L. H.; CARVALHO, A. M. P. Alfabetização científica: uma revisão bibliográfica. Investigações em ensino de ciências, v. 16, n. 1, p. 59-77, 2016.

SCHUCHMANN, A. Z.; SCHNORRENBERGER, B. L.; CHIQUETTI, M. E.; GAIKI, R. S.; RAIMANN, B. W.; MAEYAMA, M. A. Isolamento social vertical X Isolamento social horizontal: os dilemas sanitários e sociais no enfrentamento da pandemia de COVID-19. Brazilian Journal of Health Review, v. 3(2), p. 3556-3576, 2020.

VENAGLIA, G. Mandetta rejeita decreto para cloroquina e pede que médicos 'convençam pares'. CNN Brasil, 2020. Disponível em: https://www.cnnbrasil.com.br/saude/2020/04/07/mandetta-rejeita-decreto-paracloroquina-e-pede-que-medicos-convencam-pares. Acesso em: 24 out. 2020.

TELESSAUDERS. Qual a diferença de distanciamento social, isolamento e quarentena? Disponível em: https://www.ufrgs.br/telessauders/posts_coronavirus/qual-a-diferenca-de-distanciamento-social-isolamento-equarentena/. Acesso em: 23 maio 2020. 